\title{
A review of Effect the Zinc Oxide deposition on Crystalline Silicon Solar Cells
}

\author{
Ali Kadhim Naser ${ }^{1}$, Dhafer Manea.Hachim², Qahtan A Abed ${ }^{3}$ \\ \{alikadhim558@gmail.com ${ }^{1}$,coj.dfr@atu.edu.iq ${ }^{2}$, qahtan.abed@atu.edu.iq ${ }^{3}$ \} \\ Engineering Technical College / Najaf, Al-Furat Al-Awsat Technical University, 31001 Najaf, \\ $\operatorname{Iraq}^{1,2,3}$
}

\begin{abstract}
Zinc oxide ( $\mathrm{ZnO})$, a direct bandgap semiconductor, provides tremendous promise in various applications, such as optical waveguides, clear conductive oxides, and chemical gas sensors. It is also used in UV-light emitters, piezoelectric transducers. $\mathrm{ZnO}$ is in various forms, such as nanoparticles, Nano-belts, Nano-rods, nano-tubes, and nanowires. The purpose of this research is to review a general overview of $\mathrm{ZnO}$ and its application, the use of $\mathrm{ZnO}$ as an anti-reflection coating with various styles on the solar cells, and the conventional and unconventional techniques that had been used to coating the anti-reflection layers on the solar cell will be reviewed. This is based on a review of previous studies related to applications of anti-reflective coatings of $\mathrm{ZnO}$ and make a comparison of practical results was obtained with different semiconductor materials (SIC, TiO2, ZnS, SiO2, SiN4).
\end{abstract}

Keywords: zinc oxide, anti-reflection coating.

\section{Introduction}

Renewable energies are relevant because they are created instead of conventional production from environmentally friendly [1]. A fossil-fuel-based technology source, and cause pollution to the atmosphere. Solar power is a perfect source of renewable energy that is clean, safe, and unrestricted. The Sun uses a thermonuclear process to turn $650,000,000$ tons of hydrogen into helium to provide its energy. This system produces heat and electromagnetic radiation. That flows then through the atmosphere in all directions. Just 57 percent reaches the earth's surface in these radiations, which are $1.6 \times 1018$ units of sun energy [1].

The wavelength of a photon and its energy values are strictly relative to each other. Sunlight consists of a 44-percent amount of visible light, a 3-percent portion of ultraviolet light at ground level, and the rest is infrared light. Although the overall volume of UV radiation hitting the planet is 77 percent of the total solar UV radiation, only infrared light does contact the earth. High-frequency radiation is absorbed by photovoltaic cells, including ultraviolet (UV) and visible light, which converts it into energy. Although low-frequency radiation is infrared radiation, it is usually converted into heat or thermal radiation [2].

The first type of photovoltaic developed was silicon solar cells. In Sun PV, crystalline cells have to be played within two respects, with CPF in the monocrystalline cell and CIGS in the polycrystalline cell. As their manufacturing processes are quick and low-cost, polycrystalline 
cells are more comprehensive than monocrystalline cells. Monocrystalline cell production is $15-20 \%$, whereas polycrystalline cell output is $12-17 \%$ [3][4].

There are essentially two explanations for a solar panel's decreasing efficiency: soil and reflection. The sunlight gets to the panel's surface above a certain angle, passes via the glass panel, and then enters the cell. 8-10percentage of the light was reflected from a glass surface and was not transmitted to the cell. About 35 to 36 percent of light hitting the solar cell silicon substrate reflects. An optical, electrical power loss occurs from the absorption of the Sun's rays[5]. Consequently, decreasing optical losses are factors that improve the performance of PV cells. This paper investigates the application of anti-reflective coatings (ARC) to silicon and glass substrates to minimize solar cell optical losses, investigates the physics of ARC, fabrication techniques for ARC, and compares zinc oxide and different semiconductors materials with Nano sizes as antireflection coatings. Naji et al. (2021) investigated the blending process of different Iraqi oils and its effect on obtained blend API gravity and sulfur content. They also simulated the fractionation process of different blends to predict atmospheric distillation products' yields and quality.

\section{Literature Studies}

As an important ARC for energy conversion efficiency enhancement, this study investigates the synthesis of zinc-oxide nanowire arrays on Si micro pyramids. As a result, this structure indicates suppressing bandwidth reflection in the $300-1200 \mathrm{~nm}$ range, with a 3.2 percent scale weighted reflectance. The conversion efficiency was $16.0 \%$, which is the highest for most solar cells[2]. Method of preparation of $\mathrm{ZnO}$ for easy and inexpensive chemical bath deposition Nanorod arrays (NRAs) and their use as an anti-reflective coating in polycrystalline silicon cells. The zinc oxide NRAs have been shown to have a full crystalline wurtzite structure of about 40-50 nm diameter. The conversion efficiency increases from 2.27 percent to 6.61 percent after the deposition of ZnO NRAS antireflection coating [3]. The use of $\mathrm{ZnO}$ thin films as antireflective solar cell layers is seen in this study. The thin film was synthesized by sol-gel and then, using the spin-coating technique, placed on a P-N silicon substratum. The results showed that a nanostructured zinc oxide layer with hexagonal crystalline phase and particle sizes $30-50 \mathrm{~nm}$ was successfully grown on this silicone substrate. $\mathrm{ZnO}$ nanorods were produced using hydrothermal methods as an antireflection coating in a commercially available microwave oven (ARC). Relative improvement is more than 65 percent in the reflectivity was investigated via $\mathrm{ZnO}$ nanorods for both textured and planar Si surfaces, lifetime (miteff) measurement was presented, and test to be increased. As compared to the ARC of $\mathrm{ZnO}$ nanorods. [4] This research shows that $\mathrm{ZnO}$ nanopyramid structures on $\mathrm{Si}$ substrates are manufactured through an electrochemical low-temperature deposition the nanostructures were investigated concerning nanorods and planar $\mathrm{ZnO}$ texture on $\mathrm{Si}$ substrates for their antireflection (AR) properties. Reflectance spectra observe that the texture based on nanopyramid reduced light reflections from 380 to $1000 \mathrm{~nm}$ in a broadspectrum and is far more efficient than planar textures and nanorod [5]. Using the Zno granulate source thermal chemical vapor deposit, $\mathrm{ZnO}$ nanowires are synthesized to increase significant $\mathrm{Si}$-solar cell output using a simple and cost-effective process. The nanowires are generated at different levels of $\mathrm{O} 2$ flow. Notice that spectral reflectivity reduction and downshifting process as well as photon trapping reduction also enhance the efficiency of Sisolar cells and enhance the fill factor of $\mathrm{ZnO}$ nanowires of different diameters have different effects on the characteristics of silicon solar cells [6]. Enhancement by zinc oxide nanowhisker of silicon solar cells, thereby improving solar cell characteristics. The zinc oxide 
Nanowire array coated with the solar cell has a broadband reflection of 500 to $1,100 \mathrm{~nm}$, and the lowest possible reflection of less than 3 percent can be easily achieved [7]. This research examines Nanocrystalline Zinc oxide film applied by the ultrasonic spray-on substrate of textured silicon as an antireflective sheet. It was noted that the $\mathrm{ZnO}$ film crystallites' favored growth orientation is along the c-axis with a hexagonal wurtzite phase and a small tensile strain value of $0.26 \%$. The combination of a $\mathrm{ZnO}$ film as an anti-reflex coating minimizes reflection to 2.57 percent [8]. In this research, a vertically aligned nanorod array was mounted in the antireflection (AR) layer on the $\mathrm{Si}$ solar cells' substrate. We found that nanorod morphology, driven by synthetic chemistry, significantly impacts the AR layer's efficiency. We also showed that the performance of light-harvesting in solar cells increased greatly from 10.4 to 12.8 percent by using zinc oxide Nano-rod as the ARC in a multi-crystalline silicon solar cell [9]. This paper study Synthesized nanoparticles through a microwave process and developed a spin-coating technique to manufacture thin film on a silicon substrate, and examined the efficiency of a $\mathrm{ZnO}$ nanoparticle covered silicone solar cell doped with iron differing (0-20 percent). Both J-V and EQE specification for the $180.29 \mathrm{~mm}$ thick of Zinc oxide was observed for improved silicon solar cell performance. and The efficiency of power conversion was improved by about 30 percent iron-doped $\mathrm{ZnO}$ thin film and the same thick $\mathrm{ZnO}$ layer [10]. The anti-reflective coating properties of zinc oxide Nano-needles for Silicon solar cells are being investigated. After using $\mathrm{ZnO}$, the reflection spectrum induces more light emission due to low reflection around the spectral spectrum of the visible field [11]. Easy-low temperature precipitation $46-87 \mathrm{~nm}$ Nano diameters synthesis in this study and investigation of silicon solar cell coating with un-doped and cobalt-doped zinc oxides (5 percent, 10 percent, 15 percent, and 20 percent), A simple spin has put doped and undoped zinc oxide thin films silicon solar cell coating technique. Improvement in PV cell characteristics and external quantum efficiency was observed with increasing optical bandgap with increase $\mathrm{ZnO}$ coating [12]. In this research, we have developed multi-scaled hierarchical $\mathrm{ZnO}$ nanostructures on plasma-enhanced chemical vapor deposited in silicone nitride-coated textured singlecrystalline silicon solar cells for antireflective purposes, The multi-scaled hierarchical $\mathrm{ZnO}$ doped Er nanostructures looked like needles Nanotip arrays and hydrothermal have been built. The effect of the growth time on EZO NTAs microstructures has been studied, The EZO NTAs, growing for 60 minutes, demonstrated the best photovoltaic and antireflective efficiency. The conversion efficiency was established to be raised from $15.64 \%$ to $17.41 \%[12]$.

\section{Basic Concept Anti-Reflection Coating}

L. Rayleigh unintentionally discovered the idea of the antireflective coating. In 1917, however, Fraunhofer developed the first genuine anti-reflector in the 19th century.[7] Coating, the substratum surface with a transparent material with the optical path variance decreases the reflection. These coatings are called "coatings against reflection." The reflected light is built as disruptive interference, whereas the transmitted light is constructive interference. Construction interference increases the light intensity transmitted, whereas the disruptive interference of the light reflected prevents light transmission[1].

Some applications require antireflection coatings not only for the reduction of reflection but also for a substantial increase in transmission [6]. When two light waves interact with a $\pi$ phase difference, the waves interfere destructively. If all waves have the same magnitude, the net amplitude will be zero. In this situation, the incident light reflectance may be decreased or even reduced to zero with disruptive interference [7]. The reflection loss at an interface is 
minimized by the two surrounding media if a thin material layer has a refractive index value, The possible configuration is seen in Fig 1.

If there is light from a refractive index medium (n0) to another medium (n2) with a thin intermediate refractive index layer (n1), two interfaces are formed. Consequently, both interfaces reflect. The difference in path length between the two reflected rays, which Is based on the middle layer's optical Thickness, induces a phase difference resulting in constructive or destructive interference. If the middle layer is one-quarter wavelength thick, the path difference results in a $\pi$ phase difference that contributes to harmful interference. Thus, The wavelength and very poor reflectance too particles the nearby wavelengths decrease towards non reflected [8].

Anti-reflex coatings can range from a single layer with virtually zero reflectance at just a single wavelength to a multilayer system with a more extensive layer, with almost zero reflection over a range of wavelengths [9].

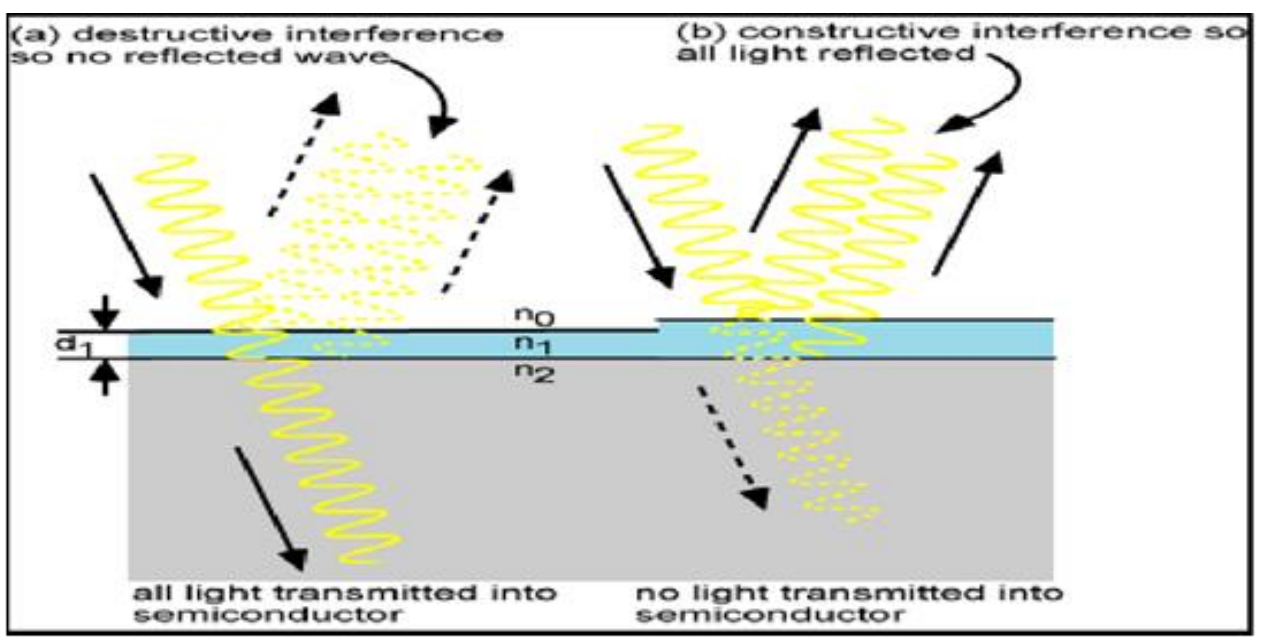

Fig 1. Shows prospective configurations [8].

\section{Anti-Reflecting Coating Styles}

\subsection{ARC Single-Layer}

A single-layer ARC aims to achieve destroying Light incident interference by generating an optical path gap of $\pi / 2$. Single-layer ARC was considered moderately, Restriction of reflection at a specified wavelength. The substrate used for silicon solar cells can be suitable for singlelayer ARC [6]. Titanium dioxide, silica, zinc oxide, and so forth. Were studied to reduce reflectivity and improve their performance. Here, it must be noted that the use of an antireflective film on glass with a relatively low refractive index $(n=1.22)$ poses a challenge to finding a material that has a lower refractive index than the glass to reduce the reflection losses on the glass [6][10]. 


\subsection{The Multi-Layer ARC}

Multiple layers of ARC are meant to remove reflectance over a broader range than the ARC single layer. For example. with the same optical effect, two layers or bilayer ARC will perform zero reflectance " $(\mathrm{n} 1 \mathrm{~d} 1=\mathrm{n} 2 \mathrm{~d} 2=\lambda / 4)$ " Thickness [11], If a high index coat is used, for example, a polycrystalline aluminum oxide $(n=1.69)$ is present before a low index $(n=$ 1.05) coated interface where the index convergence is high (such as a refractive index magnesium fluoride 1.38). The double-layer alternating RC reflects a V-shaped dip. The three-layer ARC achieved reflection reduction across a far more extensive spectrum, from thin films to membranes and other polymer-ceramic biomaterials. [6]. Figure.2, The glass substrate's patterns define 2 The reflecting single layer, double layer, and tri-layer. Reflection is taken from a single layer on a glass substrate. , A, B, C, respectively [6].

\section{Anti-Reflecting Coating Techniques}

Most nanotechnology ARCs can be fabricated by either subtractive top-down or bottomup manufacturing methods. Fig 2, Denote A comparison of particle-deposition methods used to prepare AR coatings.

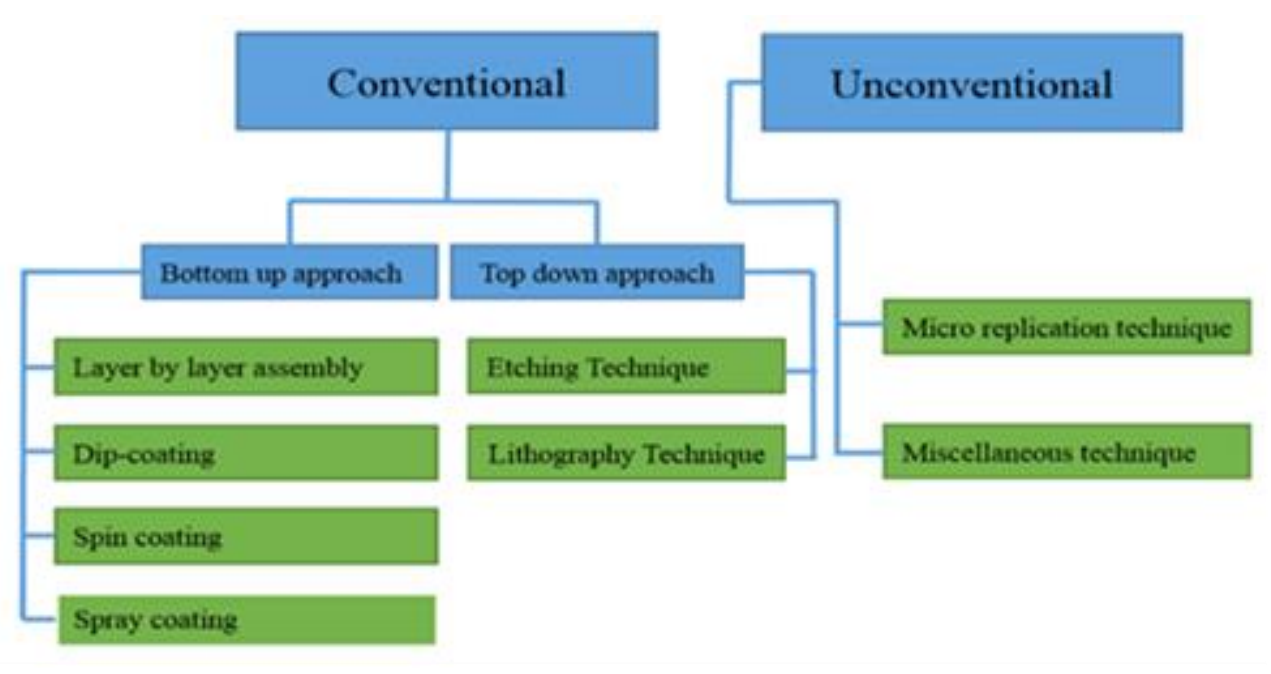

Fig 2. anti-reflecting coatings fabrication process [5].

\subsection{Sol-Gel Process}

The most popular strategies for adsorption and recovery of ARC are dip-coating and spincoating. The substrate is dipped into a precursor solution in the dip method coating system and withdrawn at a controlled speed [6]. In contrast, spin-coating involves rotating the substrate at a steady rate, while a precursor is dispensed on its surface. The precursor is mixed in an organic solvent that contains the metal-organic compound. The solution is either spun onto the 
substrate or dipped onto the substrate and then dried away with the solvent's evaporation.[14]. The film then undergoes a final heat treatment in which the organic residue is removed, causing the film to be either metal oxide or fluoride. The sol-gel method has been utilized to produce commercial-scale amounts of ARC-grown glasses for over 40 years [6].

\subsection{Vapor deposition process}

The most widely used industrial method for manufacturing anti-reflective coatings is the vapor deposition technique [11]. Plasma-enhanced deposition of chemical vapor (PECVD) is a technology used to deposit semiconductors onto silicon wafers. This method is widely used in ARC manufacture silicon $(\mathrm{NaNx}: \mathrm{H})$ coatings on textured silicon solar cells. In which, it is apparent that $\mathrm{SiNx}$ is a coating on crystalline silicon solar cells textured. The silicon nitride coatings are usage an antireflection layer and a Passivation layer of surface for silicon solar cells [10]. For example, in the deposition method often a palladium species is used with ammonia or amine. The first volatile chemical is poured onto a hot board. Unique technologies such as plasma-assisted evaporation (PAD) and plasma modified evaporation processes can apply to strongly clean transparent glass substrates (e.g., dielectrics), GaN substrates have been produced as polymer substrates. To decrease or stop scratching from occurring, industries worldwide have looked at different ways to eliminate the presence of scratches, building coatings composed of reflective and scratch resistance [15]. A vapor deposition technique has been utilized to deposit the GRIN ARC on Si. like the technology which is using a new method called glancing angle deposition (GLAD).

\subsection{Etching}

Techniques like etching have been employed to produce near-field optical coatings and optical colloids like moth's eye-like structures to offer antireflective characteristics. This method has been standard for many years, using masks or particles that mimic masks [16][17]. As an illustrative case, a monolayer of self-assembled nanostructures such as silicon nanoparticles acted as a mask to etch a silicon substrate to fabricate interconnected ARCs [18]. To build the mask on Si substrates and conducted an SF6 dry etching to produce Moth's eye nanomaterials. It was calculated that the quantity of reflectance for silicon substrates was reduced to $2.5 \%$ and the measurements of the Moth's eye nanostructures on the substrate were found to be of the same size as well as the same duration of the etching [19].

\section{Comparison of the Impact of Different Semi-Conductor Materials as ARC-Layers}

As depicted in Table1, shows the comparison with practical results in terms of various semi-conductors were used and the relationship between reflection value and layer thickness, wavelength, and consequently the solar cell's electrical characteristics related to the reflection value was obtained.

The film thickness of the anti-reflection layer deposited on the solar cell plays the main role in the reflection value and so on it is not easy to be adjusted to obtain the fit layer thickness, Film thickness must be optimized to get an optimal level of VOC and ISC. According to table 1, for example, the optimum thickness of $\mathrm{SiC}$ ARC was $36.159 \mathrm{~nm}$, and so on the maximum efficiency was 16.06 percent has been achieved for that thickness. The highest performance 
was achieved with maximum VOC and ISC values of $0.6779 \mathrm{~V}$ and $2.807 \mathrm{~A}$. The optimum thickness and efficiency for solar cells made of $\mathrm{TiO} 2, \mathrm{ZnO}, \mathrm{ZnS}, \mathrm{SiO} 2$, and $\mathrm{Si} 3 \mathrm{~N} 4 \mathrm{ARC}$ are $62.396,78.411,63.479,101.351$, and $74.257 \mathrm{~nm}$, respectively. have, 19.73 percent, 20.34 percent, 19.83 percent, 18.99 percent, and 20.35 percent, respectively. The reduction in light reflection is the explanation for the increased efficiency [59]. As reflection increases, VOC, ISC, and solar cell efficiency decrease. As a result, thickness optimization played the main role to achieve the lowest reflectance and the best VOC, ISC, and consequence performance.

Table 1- Data of various semi-conductor - ARC -layers.

\begin{tabular}{|c|c|c|c|c|c|c|c|c|c|c|c|c|c|c|c|c|}
\hline \multicolumn{6}{|c|}{ ARC-SIC [60] } & \multicolumn{5}{|c|}{ ARC-TIO2[61] } & \multicolumn{6}{|c|}{ ARC-ZNO[62] } \\
\hline$\lambda$ & $\mathbf{n}$ & $\begin{array}{l}\text { Thi } \\
\text { ck } \\
\text { nm }\end{array}$ & $\begin{array}{l}\text { I } \\
\text { SC }\end{array}$ & $\begin{array}{c}\mathbf{V} \\
\text { OC }\end{array}$ & $\begin{array}{l}\eta \\
\%\end{array}$ & $\mathbf{n}$ & $\begin{array}{l}\text { Thi } \\
\text { ck } \\
\text { nm }\end{array}$ & $\begin{array}{c}\mathbf{I} \\
\mathbf{S C}\end{array}$ & $\begin{array}{c}\text { Vo }_{0} \\
\text { C }\end{array}$ & $\begin{array}{l}\eta \\
\%\end{array}$ & $\mathbf{n}$ & $\begin{array}{c}\text { Thic } \\
\mathbf{k} \\
\mathbf{n m}\end{array}$ & & I sc & $\mathbf{V}_{\text {OC }}$ & $\eta \%$ \\
\hline 25 & 3. & 19. & 2. & 0.6 & 15. & 2. & 25. & 2. & 0.6 & 15. & 2.38 & 26.17 & & 2.79 & 0.677 & 16.0 \\
\hline $\mathbf{0}$ & 25 & 2 & 6 & 765 & 14 & 46 & 4 & 78 & 7 & 9 & 8 & & & 7 & & $\mathbf{0}$ \\
\hline 30 & 3. & 21. & 2. & 0.6 & 15. & 3. & 22. & 2. & 0.6 & 15. & 2.40 & 31.19 & & 2.93 & 0.679 & 16.8 \\
\hline 0 & 52 & 2 & 6 & 765 & 10 & 32 & 5 & 71 & 7 & 4 & 4 & 8 & & 7 & $\mathbf{1}$ & 4 \\
\hline 40 & 3. & 28. & 2. & 0.6 & 15. & 2. & 37. & 3. & 0.6 & 18. & 2.11 & 47.30 & & 3.26 & 0.682 & 18.8 \\
\hline 0 & 51 & 4 & 7 & 774 & 72 & 68 & 2 & 31 & 5 & 0 & 4 & 4 & & 9 & & 2 \\
\hline 50 & 3. & 36. & 2. & 0.6 & 16. & 2. & 50. & 3. & 0.6 & 19. & 1.96 & 63.51 & & 3.46 & 0.683 & 20.0 \\
\hline 0 & 45 & 1 & 8 & 779 & 06 & 48 & 4 & 3 & 83 & 3 & 8 & 6 & & 7 & 8 & 1 \\
\hline 60 & 3. & 44. & 2. & 0.6 & 16. & 2. & 62. & 3. & 0.6 & 19 & 1.91 & 78.41 & & 3.52 & 0.684 & 20.3 \\
\hline 0 & 40 & $\mathbf{0}$ & 8 & 77 & 03 & 40 & 3 & 42 & 81 & 7 & 3 & 1 & & 3 & 3 & 4 \\
\hline 70 & 3. & 52. & 2. & 0.6 & 15. & 2. & 74. & 3. & 0.6 & 19 & 1.88 & 92.93 & & 3.47 & 0.683 & 20.0 \\
\hline 0 & 35 & 1 & 7 & 77 & 86 & 36 & 0 & 37 & 82 & 4 & 3 & 7 & & 3 & 9 & 4 \\
\hline 80 & 3. & 60. & 2. & 0.6 & 15. & 2. & 85. & 3. & 0.6 & 18. & 1.86 & 107.2 & & 3.35 & 0.682 & 19.3 \\
\hline 0 & 31 & 3 & 7 & 77 & 63 & 34 & 4 & 24 & 84 & 8 & 4 & 96 & & 9 & 9 & 6 \\
\hline 90 & 3. & 68. & 2. & 0.6 & 15. & 2. & 96. & 3. & 0.6 & 18. & 1.85 & 121.5 & & 3.22 & 0.681 & 18.5 \\
\hline 0 & 28 & 4 & 7 & 76 & 44 & 32 & 7 & 15 & 81 & 1 & 1 & 56 & & 6 & 7 & 6 \\
\hline 10 & 3. & 76. & 2. & 0.6 & 15. & 2. & 108 & 3. & 0.6 & 17. & 1.84 & 135.8 & & 3.10 & 0.680 & 17.8 \\
\hline 00 & 24 & 9 & 6 & 7 & 34 & 31 & .0 & 06 & 802 & 5 & 1 & & & 9 & 6 & 6 \\
\hline 11 & 3. & 85. & 2. & 0.6 & 15. & 2. & 119 & 2. & 0.6 & 17. & 1.83 & 150.0 & & 3.02 & 0.679 & 17.3 \\
\hline 00 & 2 & 1 & 7 & 7 & 47 & 30 & .3 & 9 & 79 & 1 & 3 & 27 & & 3 & 8 & 5 \\
\hline & & RC & $11 \mathrm{~V}$ & & & & & ARC & $\mathrm{C}-\mathrm{SiC}$ & & & & & RC- & $4[65]$ & \\
\hline$\lambda$ & n & $\begin{array}{c}\text { Thi } \\
\text { ck }\end{array}$ & $\begin{array}{c}\text { I } \\
\text { SC }\end{array}$ & $V_{\text {OC }}$ & $\eta$ & n & & $\begin{array}{l}\text { hic } \\
\mathbf{k}\end{array}$ & I $_{\mathrm{SC}}$ & VoC & $\eta$ & n & $\begin{array}{l}\text { thi } \\
\text { ck }\end{array}$ & $\begin{array}{c}\mathrm{I} \\
\mathrm{sC}\end{array}$ & $\begin{array}{c}\mathbf{V}_{\mathbf{O}} \\
\mathrm{C}\end{array}$ & $\eta$ \\
\hline 25 & 2. & 24. & 2. & 0.67 & 15. & 1.5 & & 41. & 2.7 & 0.67 & 15.7 & 2.2 & 27. & 2.8 & 0.6 & 16.0 \\
\hline 0 & 6 & $\mathbf{0}$ & 7 & 7 & 8 & 2 & & 12 & 5 & 74 & & 8 & 3 & & 77 & \\
\hline 30 & 2. & 29. & 2. & 0.67 & 16. & 1.5 & & 49. & 2.8 & 0.67 & 16.4 & 2.1 & 34. & 2.9 & 0.6 & 16.9 \\
\hline 0 & $\begin{array}{l}5 \\
7\end{array}$ & 1 & 9 & 8 & 6 & 1 & & 67 & 7 & 85 & & 6 & 6 & & 79 & \\
\hline 40 & 2. & 39. & 3. & 0.68 & 18. & 1.5 & & 66. & 3.0 & 0.68 & 17.7 & 2.0 & 48. & 3.2 & 0.6 & 18.8 \\
\hline 0 & $\begin{array}{l}5 \\
6\end{array}$ & $\mathbf{0}$ & 1 & 1 & 2 & & & 67 & 9 & 05 & & 7 & 3 & & 82 & \\
\hline 50 & 2. & 51. & 3. & 0.68 & 19. & 1.4 & & 84. & 3.2 & 0.68 & 18.6 & 2.0 & 61. & 3.4 & 0.6 & 20.0 \\
\hline 0 & $\begin{array}{l}4 \\
2\end{array}$ & 6 & 3 & 3 & 5 & 82 & & 35 & 4 & 18 & & 3 & 5 & & 83 & \\
\hline 60 & 2. & 63. & 3. & 0.6 & 19. & 1.4 & & 01 & 3.2 & 0.68 & 18.9 & 2.0 & 74. & 3.5 & 0.6 & 20.3 \\
\hline 0 & 3 & 4 & 4 & 36 & 8 & 8 & & .3 & 9 & 23 & & 2 & 2 & & 84 & \\
\hline
\end{tabular}




\begin{tabular}{|c|c|c|c|c|c|c|c|c|c|c|c|c|c|c|c|}
\hline 70 & $\begin{array}{l}6 \\
2 .\end{array}$ & 75. & 3. & 0.68 & 19. & 1.4 & 118 & 3.2 & 0.68 & 18.7 & 2.0 & 87. & 3.4 & 0.6 & 20.0 \\
\hline $\mathbf{0}$ & $\begin{array}{l}\mathbf{3} \\
\mathbf{3}\end{array}$ & 0 & 9 & 31 & 5 & 74 & .7 & 6 & 2 & & & 3 & & 83 & \\
\hline 80 & 2. & 86. & 3. & 0.68 & 18. & 1.4 & 135 & 3.1 & 0.68 & 18.2 & 1.9 & 10 & 3.3 & 0.6 & 19.3 \\
\hline $\mathbf{0}$ & $\begin{array}{l}3 \\
2\end{array}$ & 0 & 2 & 21 & 8 & 73 & .7 & 8 & 13 & & 9 & 0 & & 82 & \\
\hline 90 & 2. & 97. & 3. & 0.68 & 18. & 1.4 & 152 & 3.0 & 0.68 & 17.6 & 1.9 & 11 & 3.2 & 0.6 & 18.5 \\
\hline 0 & $\begin{array}{l}3 \\
1\end{array}$ & 4 & 1 & 11 & 1 & 72 & .8 & 7 & 03 & & 9 & 3 & & 81 & \\
\hline 10 & 2. & 107 & 3. & 0.68 & 17. & 1.4 & 169 & 2.9 & 0.67 & 17.1 & & 12 & 3.1 & 0.6 & 17.8 \\
\hline $\mathbf{0}$ & $\begin{array}{l}\mathbf{3} \\
\mathbf{0}\end{array}$ & .6 & $\mathbf{0}$ & 03 & 6 & 71 & .9 & 8 & 95 & & 1.9 & 5 & & 80 & \\
\hline 11 & 2. & 119 & 2. & 0.67 & 17. & 1.4 & 187 & 2.9 & 0.67 & 16.6 & & 13 & 3.0 & 0.6 & 17.4 \\
\hline $\mathbf{0 0}$ & $\begin{array}{l}2 \\
9\end{array}$ & .7 & 9 & 96 & 2 & 7 & .0 & 1 & 88 & & $\begin{array}{c}1.9 \\
8\end{array}$ & 8 & & 79 & \\
\hline
\end{tabular}

\section{A short review of zinc oxide.}

The semiconductor known as zinc oxide possesses considerable potential in many applications, including optoelectronic devices and organic LED whiteners. [20]. It may also be used for a variety of chemical gas sensors and spin practical instruments. For UV-light emitters, it is often used, piezoelectric transducers, and chemical sensors. For light-emitting diodes and UV or blue-spectrum photonic applications, ZnO's large bandgap makes it a promising material. While high exciton binding energy $(60 \mathrm{meV})$ will guarantee a broad range of emission characteristics even at room temperature, in addition to being far greater than that of $\mathrm{GaN}(25 \mathrm{meV})(\mathrm{RT})$ [21]. $\mathrm{ZnO}$ has several benefits as a metal oxide with a large bandgap. A higher breakdown voltage and the capacity to manage significant electrical noise and high power operation are available. Zinc oxide's piezoelectric properties and semiconducting nature make it useful for devices such as piezoelectric generators that collect electricity.[22].

A semiconducting characteristic activates the essential metal oxide for doping. aluminumdoped Zinc oxide is a wide-area node consisting of an n-type material; additives in $\mathrm{ZnO}$ alter its optical properties that can be used to tune the emission color[23]. $\mathrm{ZnO}$ is in various forms, As well as nano-engineered, nano-sized, nanostructured, and nano-building materials. And by controlling the nanostructure's morphology and size, it is easy to alter its properties. They have excellent optical and electrical properties and can be easily synthesized into different shapes, so they are possible candidates for photovoltaic (PV) implementations[24]. Some of the $\mathrm{ZnO}$ nanoparticles have low reflectivity, increasing the light absorption; $\mathrm{ZnO}$ nanostructures are typically applied as the PV systems' antireflection layer. Nanostructures of $\mathrm{Al}$ and $\mathrm{ZnO}$ are also preferable, such as metal oxide (TCO) for solar panels [21]. Table 2. Represents much of the features of zinc oxides.

Table 2. zinc oxide properties [25].

\begin{tabular}{cc}
\hline Chemical formulation & $\mathrm{ZnO}$ \\
\hline Energy gap (Eg) at room & $3.37 \mathrm{EV}$ \\
temperature & \\
Appearance & Solid \\
Colour & White
\end{tabular}




$\begin{array}{cc}\text { Crystalline structure } & \text { Hexagonal and Cubic } \\ \text { Point of melting } & 1975^{\circ} \\ \text { Density } & 5.606 \mathrm{~g} / \mathrm{cm} 3 \\ \text { Electron mass effective } & \mathrm{Me}^{*}=0.24 \mathrm{mo} \\ \text { mass effective } & \mathrm{Mh}^{*}=0.59 \mathrm{mo}\end{array}$

\subsection{Crystalline $\mathrm{ZnO}$ structure}

Gold, indium, and zinc are essential semiconductor materials. $\mathrm{ZnO}$ can be crystallized in the wurtzite, cubic Zn, and cubic rock salt systems. [27], as displayed in Fig 3. The cubic patterned structure of rock salt can be obtained at relatively high zinc oxide temperatures and pressures, Only cubic substrates may stabilize the cubic zinc blend structure. They are not known to be a standard system belonging to $\mathrm{ZnO}$ in the atmospheres. Four $\mathrm{O}$ atoms encircle each $\mathrm{Zn}$ atom at the corners of a tetrahedron and vice versa in both its hexagonal wurtzite and cubic Zn blend arrangement. [26]. The Sp3 covalent bond, eclipsed for hexagonally wurtzite, and staggered for the cubic zinc blending structure, is distinguished by this tetrahedral coordination. The ionic character of $\mathrm{ZnO}$ is also, and This leads to increased bandgap energy beyond what the strictly covalent bonding predicted.[20]

Fig 3 [28] shows the hexagonal cell with two grid constants, a and c is the wurtzite structure; the c/a ratio of a complete hexagonal structure is 1,6333. The system is composed of two hexagonally enclosed interpenetrating sublattices. One consists of $\mathrm{Zn}$ atoms, whereas the other consists of $\mathrm{O}$ atoms. They interpenetrate with each other along the c-axis with a value of $\mathrm{u}$ 0.3755 in an optimal hexagonal configuration. Where $u$ is defined as the bond length of $\mathrm{Zn}-\mathrm{O}$ parallel with the $c$-axis, which is equivalent to $(\mathrm{u}=[(1 / 3) .(\mathrm{a} / \mathrm{c}) 2)+1 / 4]) . \mathrm{X}$-ray diffraction or transmission electron microscopy at room temperature typically investigates the constants in nature (HRTEM). The surface region ranges from 3.24 to 3.25 Angstroms for a and from 5.20 to 5.25 Angstroms for c [27].

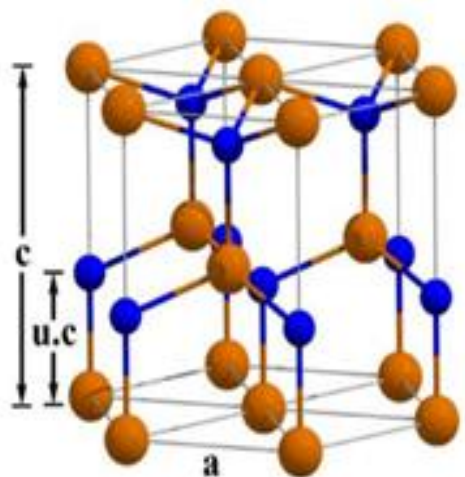

(a) wurtzite

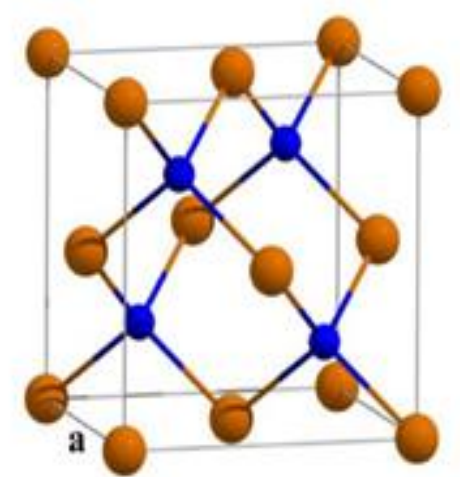

(b) zinc-blende

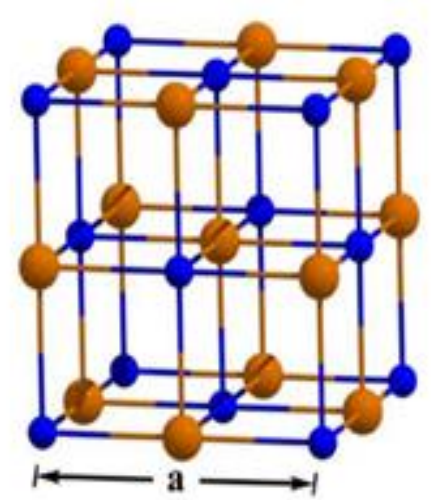

(c) rock-salt

Fig 3. Zinc oxide crystalline [28]. 


\subsection{ZnO Nanostructures Category}

From a morphological perspective, Nano-materials can be sub-divided into four categories: 0dimension (Nano-particles ), one- dimension (N-tube, NW, NRs), two-dimension (Nanolayers, Nano-plates), and three-dimension (Nano-tetrapods, Nano-flowers) [29] .There are some kinds of Nano-structures, even more exotic, like forming nano-organ-like structures. Deposition and development strategies had a significant influence on morphological developments. Morphology specifically depends on Material composition, temperatures of formation, and diffusion [30].

\subsection{Zinc Oxide Nanostructure in Solar Cell}

Nanostructure of a single dimension applies to NW, Nano-fibres, Nano-cables, NT, Nanobelt, and more[30], which are extended in one specific direction. Because of its distinctive electronic and optical properties, $\mathrm{ZnO}$ semiconducting NWs must develop nano-electronic devices. , Conversion and storage of energy (photovoltaic cells, storage systems, condensers, hydrogen storage systems), Emitting light diodes, catalysis, delivery of drugs, nano generation and piezoelectric power, A chemical growth aqueous and CVD strategies verify that a large part of the Nanowire in the array comes into close communication with the substratum [31]. Therefore, $\mathrm{ZnO}$ nanowires have an ongoing pathway for the transport of electric carriers. This is important for increasing the efficiency of other devices of this nature based on nanomaterials. ZnO Nanowire's vertical focus has excellent optoelectronic properties. Thus, the design of light-emitting diodes and photovoltaic panels has been studied; Excluding p-n junctions and dye-sensitive solar panels, modules dye-sensitized solar panels. Also, ZnO's piezoelectric and semiconductor properties lead to potential employed devices with gas sensors [32]

\section{Solar Cells}

An electrical instrument that transfers light energy to the electricity directly via a photovoltaic rection. Its photoelectric cell form is described as a device whose electrical character, for example, voltage, current, and resistance, changes in light intensity[35]. Solar cells are the main parameters of PV modules, or they are also classified as solar panels. They may be used as a photodetector, like infrared detectors, light detection, and nearby electromagnetic radiation Visible spectrum of light intensity measurement. Sir AlexanderEdmond Becquerel first coined the photovoltaic (PV) effect in 1839, Russel Ohl developed the first current silicon solar cell in 1946. Thin silicon wafers are photovoltaic solar cells that convert solar power into energy in advance. [36]. The latest photovoltaic (PV) development is focused on the idea of each cell system forming an electron-hole, which consists of two kinds of wafers ( $p$ and $n$ types ) of the semiconductor. The various materials for solar cell photovoltaic systems are primarily used in silicon ( $\mathrm{Sc}, \mathrm{Mc}$ crystallines, and amorphous silicon), Telluride of cadmium, selenide copper-indium-gallium, and indium-gallium-sulfide of copper. photovoltaics solar cell systems are classified into different groups based on these materials, as shown in Figure. 4 [37] [38]. 


\subsection{Single/Mono-Crystalline Silicon Solar Cell}

Single-crystal silicon is used as the base material with all silicon wafers equipment nowadays [39]. Monosilicon is a structural component of photovoltaic cells used in solar power production. It is a single crystal in which all of the lattice structure is continuous, uninterrupted, and devoid of grain boundaries. Mono-Si can be prepared with pure silicon or doped, containing very little to no additional elements to alter its conductivity [40]. The Czochralski method produces most silicon crystals, with crystals up to several meters long and well over a hundred kilograms in weight; The crystals are then cut down into thin, thin wafers are then further processed[41]. Single-crystal silicon is, without a doubt, the most important technological material over the last few centuries, the "silicon era" because of its accessibility at a fair cost, which has been crucial to the growth of electronic devices on which we rely today. Monocrystalline single-crystalline silicon solar efficiency Cells ranging from 17 to 18 percent[36].

\subsection{Solar Cell of Polycrystalline Silicon (Poly-Si or Mc-Si)}

Polycrystalline silicon, also known as polysilicon, Is a pure silicon form used in photovoltaic solar and electronics technology as a natural resource [39]. Polysilicon, developed through a chemical filtration system called the Siemens method, is purified from metallurgical-grade silicon. The distillation method includes the dissolution and decomposition at high temperatures of volatile silicon compounds and the subsequent release of silicon. Emerging technology in the refining process uses a fluidized bed process [42]. The solar PV industry also usages metallurgical processes rather than chemical processes to purify their products. Polysilicon used in electronics has impurities under one portion per billion, while when used for solar cell production, fewer grade purities were needed. The large polysilicon rods, usually broken into small chunks, are directly cut into individual cuboids; these individual cuboids are then cast into multi-crystalline ingots or processed to develop single crystal boules. These materials are then cut into thin silicon chips and used to manufacture solar cells, integrated circuits, and other semiconductor devices [43]. Small crystals make up polysilicon, Identified as crystallites also. Both polysilicon and multi silicon can be used interchangeably to describe silicon-based compounds; multi-crystalline usually describes crystals that are more than $1 \mathrm{~mm}$ in size. Polycrystalline Silicon solar cells are now the most commonly known Sun cells. In 2008 they were thought to account for up to 48 percent of solar cell production worldwide. Even though they are cheaper to manufacture than monocrystalline silicon solar panels, their efficiency is $\sim 12-14$ percent and hence, they are less efficient than monocrystalline [44][45]. 


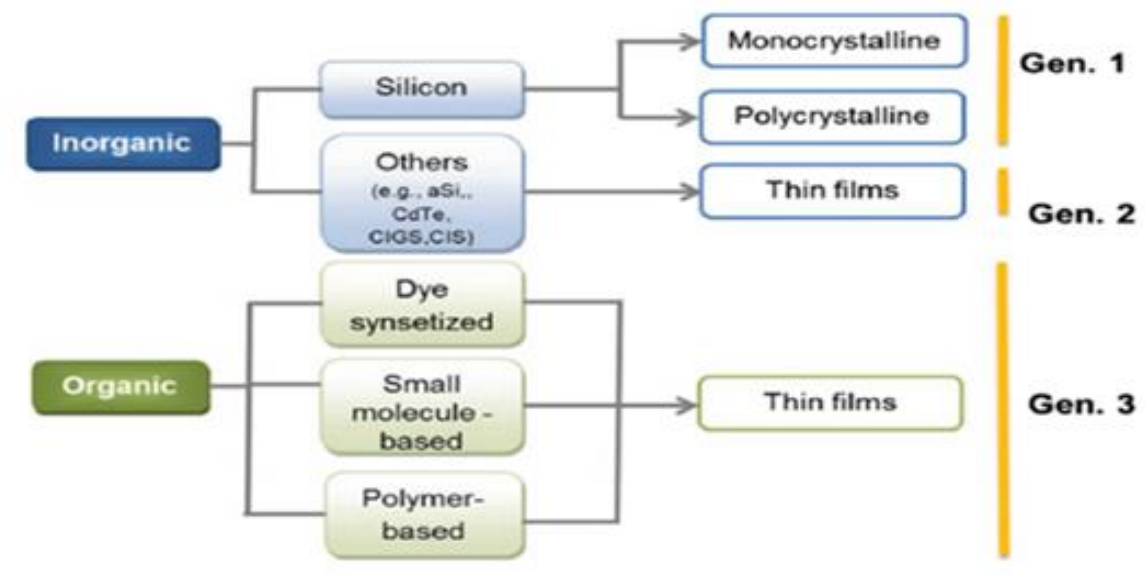

Fig. 4. Photovoltaic Solar Cell Type [37].

\section{Conclusions}

ZnO Nano sizes have high carrier density and mobility, which improves the energy efficiency of solar cells. This review discusses recent advances in ARC coatings, especially coatings containing $\mathrm{ZnO}$ nanoparticles. The development of ARC coatings is still fraught with challenges in terms of choosing the right material and ideal thickness. Anti-reflective coatings must have unique properties, for example; Thermal and mechanical stability, for use in various conditions and over long periods. The mechanical and electrical properties of $\mathrm{ZnO}$ according to published studies made it possible to use $\mathrm{ZnO}$ to create multifunctional materials with improved anti-reflection and self-cleaning properties. It can be used in solar cell components to provide high-energy conversion while also lowering costs. $\mathrm{ZnO}$ 's high strength and durable surfaces make it ideal for anti-reflective and self-cleaning applications, allowing manufacturers to use it to enhance the mechanical strength of their products.

\section{References}

[1] Z. Yao, “ ZnO Nanoparticles as a Luminescent down-shifting Layer for Solar Cells,” pp. 1-165, 2015

[2] U. Bach, "Solid-state dye-sensitized mesoporous TiO2 solar cells," EPFL, 2000.

[3] Z. Yao, "T. Nyamwanza, vol. 2014, no. June, pp. 1-2, 2014

[4] Y. Liu et al., "Hybridizing $\mathrm{ZnO}$ nanowires with micro pyramid silicon wafers as superhydrophobic high-efficiency solar cells," Adv. Energy Mater., vol. 2, no. 1, pp. 47-51, 2012.

[5] Y. Qu et al., " Chemical bath deposition produced $\mathrm{ZnO}$ nanorod arrays as an anti-reflective layer in the polycrystalline Si solar cells," J. Alloys Compd., vol. 698, pp. 719-724, 2017.

[6] P. Anurang, O. Demircioglu, F. Es, and R. Turan, "HE Unalan," J. Am. Ceram. Soc., vol. 96, no. 4, p. $1253,2013$.

[7] X. Jin et al., "Preparation of K2Ti6O13 fibers by electrospinning for near-infrared reflectivity," Ceram. Int., vol. 45, no. 11, pp. 14198-14204, 2019.

[8] X. Yu, D. et.al, "improvement of silicon solar cells efficiency by $\mathrm{ZnO}$ nanowhisker array coating," Nanoscale Res. Lett., vol. 7, no. 1,2012. 
[9] S. Sali, M. et.al, "zinc oxide Nano-crystalline film deposited by ultrasonic spray on a silicon substrate textured as the anti-reflection coating," Phys. B Condens. Matter, vol. 407, no. 13, pp. 2626-2631, 2012

[10] J. Y. Chen, et.al, "Growth of vertically aligned znic oxide nano-rod arrays as antireflection coating on silicon solar cells," Sol. Energy Mater. Sol. Cells, vol. 94, no. 5, 2010.

[11] G. R. Neupane, A. Kaphle, and P. Hari, "Microwave-assisted Fe-doped ZnO nanoparticles for enhancement of silicon solar cell efficiency," Sol. Energy Mater. Sol. Cells, vol. 201, p. 110073, 2019.

[12] M. Al-Fandi, Y. F. Makableh, M. Khasawneh, and R. Ready, "Near-zero reflection by nanostructured antireflection coating design for Si substrates," Superlattices Microstruct., vol. 117 , pp. 115-120, 2018.

[13] A. Kaphle et.al, "Enhancement the power conversion efficiency of silicon solar cells by doped zinc oxide nano-particle thin-film layers,", vol. 657, pp. 76-87, 2018.

[14] B. Liu, S. Qiu, R. Hu, Y. Liao, N. Chen, and G. Du, "Multiscaled hierarchical nanostructures for enhancing the conversion efficiency of crystalline silicon solar cells," Appl. Surf. Sci., vol. 259, pp. 705-710, 2012.

[15] H. Hanalei, et al., "Highly efficient antireflective, self-cleaning coatings that incorporate carbon nanotubes into solar cells " vol. 59, pp. 620-635, 2016, DOI: 10.1016.

[16] A. Jalali, M. Reza, V. Nima, N. Fariba, T. Abadi, and A. Eftekhari, "Investigating the effect of sol-gel solution concentration on the efficiency of silicon solar cells : role of $\mathrm{ZnO}$ nanoparticles as an anti-reflective layer," Chem. Pap., no. 0123456789, 2019, DOI: 10.1007/s11696-01900872-0.

[17] H. K. RAUT, "Studies on nanostructured antireflective coatings," 2014.

[18] K. L. Morgan, D. E. Brocker, S. D. Campbell, D. H. Werner, and P. L. Werner, "Transformationoptics-inspired antireflective coating design for gradient index lenses," Opt. Lett., vol. 40, no. 11, pp. 2521-2524, 2015.

[19] P.-F. Fu, E. S. Moyer, and C. R. Yeakle, "Method for forming an anti-reflective coating." Google Patents, Sep. 27, 2011.

[20] J. K. Holt, et al "Hotwire chemical vapor deposition of a high hydrogen content nitride for solar cell passivation, antireflection applications,", vol. 430, no. 1-2, 2003

[21] S. Chattopadhyay, et.al, "Anti-reflecting and photonic nanostructures," Mater. Sci. Eng. R Reports, vol. 69, no. 1-3, pp. 1-35, 2010.

[22] B. Sheldon, J. S. Haggerty, and A. G. Emslie, "Exact computation of the reflectance of a surface layer of arbitrary refractive-index profile and an approximate solution of the inverse problem," JOSA, vol. 72, no. 8, pp. 1049-1055, 1982.

[23] P. G. Verly, et.al, "Fourier-transform method for the design of wideband antireflection coatings," vol, 31, no. 19. 1992.

[24] D. Chen, "Anti-reflection made by sol-gel processes: a review," Sol. Energy Mater. Sol. Cells, vol. 68, no. 3-4, pp. 313-336, 2001.

[25] Z.-P. Yang, L. Ci, J. A. Bur, S.-Y. Lin, and P. M. Ajayan, "Experimental observation of an extremely dark material made by a low-density nanotube array," Nano Lett., vol. 8, no. 2, pp. 446-451, 2008.

[26] K. C. Sahoo et al., "Fabrication of antireflective sub-wavelength structures on silicon nitride using nanocluster mask for a solar cell application," Nanoscale Res. Lett., vol. 4, no. 7, p. 680, 2009.

[27] Z. Huang, et.al "a review assisted Metal chemical etching of the silicon: Ulrich Gösele," Adv. Mater., vol. 23, no. 2, 2011.

[28] H. L. Chen, et.al, "Using lithography colloidal for optimizing sub-wavelength pyramidal and honeycomb structures in solar cells," Opt. Express, vol. 15, no. 22, 2007.

[29] H. Xu et al., "Biomimetic antireflective Si nanopillar arrays," Small, vol. 4, no. 11, 2008.

[30] Z. Yao, "ZnO Nanoparticles as a Luminescent down-shifting Layer for Solar Cells," pp. 1-165, 2015, [Online]. Available: http://theses.insa-lyon.fr/publication/2015ISAL0090/these. 
[31] B. Chen et al., "Graphene coated $\mathrm{ZnO}$ nanowire optical waveguides," Opt. Express, vol. 22, no. 20, pp. 24276-24285, 2014.

[32] M.-J. Chenet.al, "ZnO- ultraviolet light-emitting and nanostructures fabricated by atomic layer deposition," Semicond. Sci. Technol., vol. 27, no. 7, 2012.

[33] B. Kumar and S.-W. Kim, "Energy harvesting based on semiconducting piezoelectric ZnO nanostructures," Nano Energy, vol. 1, no. 3, pp. 342-355, 2012.

[34] S. Xu and Z. L. Wang, "One-dimensional ZnO nanostructures: solution growth and functional properties," Nano Res., vol. 4, no. 11, pp. 1013-1098, 2011.

[35] C. F. Klingshirn, et.al, ZnO: fundamental properties towards the novel applications, vol. 120. Business Media \& Springer Science 2010.

[36] Ü. Özgür, and H. Morkoç Zinc oxide: device technology and fundamentals, materials, John Wiley \& Sons, 2008.

[37] H. Daniel, et.al, "An integrated method to realizing high-performance liquid junction sensitized solar cells quantum dot," Nat. Commun., vol. 4, no. 1, 2013.

[38] T. Wonglakhon, "Interaction potentials for modeling $\mathrm{GaN}$ precipitation and solid-state polymorphism," 2020.

[39] V. V Pokropivny, et.al." Classification of nanostructures by dimensionality, the concept of forms engineering in nanomaterial science," Mater. Sci. Eng. C, vol. 27, no. 5-8, 2007.

[40] V. Cauda et al., Nanostructured Zinc oxide Materials: Synthesis, and Applications. 2014.

[41] B. Weintraub, et.al, " synthesis of one-dimensional zinc oxide Nanosize and the applications," Nanoscale, vol. 2, no. 9, pp. 1573-1587, 2010.

[42] X. S. Shen, et.al," silver Nanoparticles: agglomeration, control the surface morphology, and application as SERS substrates," Phys. Chem. Chem. Phys., vol. 11, 2009.

[43] Y. Zhu et al., "Multiwalled carbon nanotubes beaded with $\mathrm{ZnO}$ nanoparticles for ultrafast nonlinear optical switching," Adv. Mater., vol. 18, no. 5, pp. 587-592, 2006.

[44] Q. Lu, Z. Wang, et.al, " photoluminescent properties of zinc oxide encapsulated in mesoporous silica SBA-15 fabricated by two-solvent strategy," Nanoscale Res. Lett., vol. 4, no. 7, 2009.

[45] M. RPSGOI and A. Yadav, "improve the efficiency of the photovoltaic through P\&O algorithm,". Res. Eng., vol. 2, pp. 2642-2644, 2015.

[46] K. H. Raut D. W. Deshmukh, " Comparative of the Studies of Diverse Generation in Solar Cell :" vol. 1, no. 3, pp. 1-9, 2018.

[47] A. S. Sarkın, et.al, "A review of self-cleaning and anti-reflection on the solar cells -," Sol. Energy, vol. 199, no. June 2019, pp. 63-73, 2020, DOI: 10.1016/j.solener.2020.01.084.

[48] R. N. Castellano, PV panel processing. Archives contemporaines, 2010.

[49] A. Mohammad Bagher, " Solar Cells Types, Application," Am. J. Opt. Photonics, vol. 3, no. 5, DOI: $10.11648 /$ j.ajop. 2015

[50] S. Dimitrijevic, Principles of semiconductor devices. Oxford university press New York, 2012.

[51] W. Hwang and K. H. Zaininger, "Silicon: the semiconductor material," in Silicon, Springer, 2004, pp. 25-42.

[52] F. C. Krebs, "Polymer solar cell modules prepared using roll-to-roll methods: knife-over-edge coating, slot-die coating and screen printing," Sol. Energy Mater. Sol. Cells, vol. 93, no. 4, pp. 465-475, 2009.

[53] C. J. Brabec, et.al, "Sol. Energy Mater," Sol. Cells, vol. 30, no. 83, p. 273, 2004.

[54] T. Saga, "Nanoparticles Materials 2, 96-102 (2010)." 2010.

[55] C. Bosserelle, E. S. Reddy, and E. J. Krüger, "WavesE andE Coasts inE theE Pacific."

[56] A. Jalali, M. Reza, V. Nima, N. Fariba, T. Abadi, and A. Eftekhari, "Investigating the effect of sol-gel solution concentration on the efficiency of silicon solar cells : role of $\mathrm{ZnO}$ nanoparticles as an anti-reflective layer," Chem. Pap., no. 0123456789, 2019, DOI: 10.1007/s11696-01900872-0.

[57] B. Kumaragurubaran and S. Anandhi, "Reduction of reflection losses in a solar cell using antireflective coating," in 2014 International Conference on Computation of Power, Energy, Information and Communication (ICCPEIC), 2014, pp. 155-157. 
[58] S. R. info. [Online]. https ://refra ctive index .info/ and tmp/data/main/SiC/Larru quert . txt. A. 14 J. 2018, "SiC.".

[59] T. R. info. [Online]. https ://refra ctive index .info/ and tmp/data/main/TiO2/Siefk e. txt. A. $14 \mathrm{~J}$. 2018, "TIO2 refractionindex.".

[60] L. Fanni et al., "the porosity of zinc oxide electrodes: from dense to Nano-pillar coating," Mater. Res. Express, vol. 2, no. 7, 2015. 